\title{
Effect of the immune modulating agents cyclophosphamide, methotrexate, hydrocortisone, and cyclosporin $A$ on an animal model of granulomatous bowel disease
}

\author{
I C Mitchell, J L Turk
}

\begin{abstract}
This study was undertaken to determine the effect of cyclophosphamide, methotrexate, hydrocortisone, and cyclosporin $A$ on a model of granulomatous infiltration in the terminal ileum and draining lymph nodes of the guinea pig. Treatment groups of six animals were used and compared to untreated groups of 12 . Epithelioid cell granulomas and primary macrophage granulomas were induced by the inoculation of BCG (Pasteur) and irradiated Mycobacterium leprae respectively into the terminal ileum of the guinea pig. The response to purified protein derivative of tuberculin was reduced in both groups of animals receiving any of these agents. Cyclophosphamide and methotrexate treated animals inoculated with BCG or $M$ leprae showed a significant reduction of granulomatous infiltration at the inoculation site $(p<0.05$ and $p<0.001$ respectively). BCG inoculated animals treated with either hydrocortisone or cyclosporin A showed no reduction in granulomatous infiltration at either the inoculation site or the draining lymph nodes. By contrast $M$ leprae inoculated animals receiving either of these agents showed a significant reduction of granulomatous infiltration at both the inoculation site $(p<0.001)$ and in the primary draining lymph node $(\mathbf{p}<0.001)$. Ziehl Neelsen staining showed an increased proportion of animals with detectable acid fast bacilli (AFB) at the inoculation site in the groups receiving hydrocortisone $(50 \%)$ and methotrexate $(67 \%)$ compared to untreated controls (8\%). No AFB were observed in any of the animals inoculated with $M$ leprae. In conclusion, this model may be helpful in elucidating the mechanism of $T$ lymphocyte response in Crohn's disease and the variable clinical response seen with the use of immunosuppressive agents in this condition.
\end{abstract}

We recently reported on an animal model of graulomatous bowel disease ${ }^{1}$ created by the direct inoculation of mycobacteria into the bowel wall of the guinea pig. Using this system we have been able to produce infiltration of the inoculation site and draining lymph nodes with either an epithelioid cell granuloma using BCG or a predominantly macrophage granuloma using irradiated Mycobacterium leprae. This model has enabled us to undertake a study of the effects on these differing types of granuloma, induced in the gastrointestinal tract, of a variety of immune modulating agents acting at varying stages in the immune response.

Cyclophosphamide and methotrexate were chosen as their effects on the immune system in the guinea pig have already been extensively investigated. ${ }^{23}$ Hydrocortisone is of interest because prednisolone was the first drug shown by controlled trials ${ }^{4}$ to be effective in the treatment of Crohn's disease, and, with other glucocorticoids in systemic and topical forms, has remained a mainstay of treatment. Cyclosporin A was studied because of its unique mechanism of action ${ }^{5}$ and its putative role ${ }^{67}$ as a second line agent in the treatment of refractory or relapsed Crohn's disease.

\section{Materials and methods}

ANIMALS

Outbred Hartley strain female guinea pigs weighing 300 to $430 \mathrm{~g}$ were used. They were fed on an RGP pelleted diet supplemented with cabbage.

\section{MYCOBACTERIA}

Live BCG was of the Pasteur strain obtained by courtesy of the Institut Pasteur, Paris. Cobalt irradiated armadillo derived $M$ leprae was obtained through the courtesy of Dr R J W Rees, National Institute for Medical Research, Mill Hill, London. The mycobacteria were obtained as a suspension in saline. The BCG organisms were counted by the method of Miles and Misra ${ }^{8}$ for viable organisms. $M$ leprae were counted by the method of Hart and Rees, ${ }^{9}$ which gives a count of the total number of intact organisms. Live $M$ leprae were not used because of legal restrictions owing to its pathogenicity in humans.

\section{LAPAROTOMY}

Laparotomy was performed using a procedure that we developed and fully described in a previous publication.' Briefly, animals were anaesthetised and using an aseptic technique laparotomy was performed through a midline incision. This approach gives ready access to the terminal ileum. The abdomen was closed using Vicryl sutures (Ethicon UK), the skin closure being reinforced with Histoacryl tissue adhesive

(B Braun Melsungen AG, West Germany). 
INOCULATION

All inoculations were of $50 \mu \mathrm{l}$ and standard doses of organisms were used - namely, $2 \times 10^{7}$ BCG and $2 \times 10^{9}$ irradiated $M$ leprae. Inoculation was performed using a Hamilton microlitre syringe and a $32 \mathrm{G}$ needle into the serosa of the antemesentric wall of the bowel at the level of the terminal ileal Peyer's patch.

The doses used were based on those used in earlier work $^{1}$ in which they produced a satisfactory granulomatous infiltration in the terminal ileum and its draining lymph nodes and induced sensitivity to $25 \mu \mathrm{g}$ of purified protein derivative of tuberculin (PPD) on skin testing. This dose produces no response in the unsensitised guinea pig. ${ }^{10}$

\section{CONTROLS}

Control animals were inoculated identically but received no drug treatment.

\section{DRUGS}

Cyclophosphamide (Endoxana, Boehringer Ingelheim Hospital Division) was given at a rate of $10 \mathrm{mg} / \mathrm{kg}$ body weight daily by intraperitoneal injection. Methotrexate sodium solution for injection (Lederle Laboratories) was given at a dosage of $5 \mathrm{mg} / \mathrm{kg}$ every second day by intraperitoneal injection. Hydrocortisone sodium succinate (Efcortelan, Glaxo Laboratories) was given as a solution in water subcutaneously at a dose of $0.6 \mathrm{mg} / \mathrm{g}$ body weight daily. Cyclosporin A was supplied courtesy of Dr J Borel (Sandoz, Basel, Switzerland) and given at a dose of 50 $\mathrm{mg} / \mathrm{kg}$ body weight daily as an intramuscular injection in $0.05 \mathrm{ml}$ absolute alcohol to avoid the use of oil based solvents. A further group of animals received $0.05 \mathrm{ml}$ absolute alcohol daily as a control.

All animals apart from those in the hydrocortisone group underwent laparotomy on day 0 and started drug treatment on day 2 . Animals receiving hydrocortisone were treated from day 0 with this drug before laparotomy and inoculation with mycobacteria on day 14 . All drugs were continued to the time of harvesting.

The doses of cyclophosphamide and methotrexate were based on those known to produce a loss of the delayed hypersensitivity reaction to picryl chloride and 2 phenyl-4-ethoxymethylene-5-oxazolone (oxazolone) in guinea pigs previously sensitised to them. ${ }^{3}$

The doses of hydrocortisone and cyclosporin

TABLE I Reaction to $25 \mu \mathrm{g}$ of intradermal purified protein derivative of tuberculin after 24 hours, expressed as mean $(S D)$ change in skinfold thickness $(\mathrm{mm})$

\begin{tabular}{|c|c|c|}
\hline & $\begin{array}{l}2 \times 10^{7} B C G \text { in } \\
\text { terminal ileum }\end{array}$ & $\begin{array}{l}2 \times 10^{4} \text { irradiated } \mathrm{M} \text { leprae } \\
\text { in terminal ileum }\end{array}$ \\
\hline $\begin{array}{l}\text { Cyclophosphamide } 10 \mathrm{mg} / \mathrm{kg} \text { intraperitoneally } \\
\text { daily }^{\star}\end{array}$ & $0.11(0.12) \mathrm{p}<0.01$ & $0.033(0.05) \mathrm{p}<0.005$ \\
\hline $\begin{array}{l}\text { Methotrexate } 5 \mathrm{mg} / \mathrm{kg} \text { intraperitoneally on } \\
\text { alternate days }\end{array}$ & $0.083(0.12) \mathrm{p}<0.01$ & $0.25(0.3) \mathrm{p}<0.01$ \\
\hline $\begin{array}{l}\text { Hydrocortisone } 0.6 \mathrm{mg} / \mathrm{g} \text { subcutaneously daily } \\
\text { Cyclosporin A } 50 \mathrm{mg} / \mathrm{kg} \text { in } 0.05 \mathrm{ml} \text { absolute }\end{array}$ & $0.18(0.14) \mathrm{p}<0.01$ & $0.18(0.18) p<0.01$ \\
\hline $\begin{array}{l}\text { alcohol intramuscularly daily } \\
\text { Absolute alcohol } 0 \cdot 05 \mathrm{ml} \text { intramuscularly daily }\end{array}$ & $\begin{array}{l}0.33(0.5) p<0.05 \\
0.525(0.54) \text { not } \\
\text { significant }\end{array}$ & $0.14(0.18) p<0.01$ \\
\hline Untreated $\dagger$ & $1 \cdot 2(0.8)$ & $1.06(0 \cdot 6)$ \\
\hline
\end{tabular}

${ }^{\star}$ Mean (SD) of six animals; †Mean (SD) of 12 animals

$\mathrm{p}=$ probability by comparison with untreated controls by Student's $t$ test.
A were based on those previously shown" to produce a significant depression of the response to $25 \mu \mathrm{g}$ PPD in guinea pigs inoculated with an identical dose of BCG in the ear over a similar time span. The doses of all the drugs are in the human therapeutic range.

SKIN TESTS

Twenty four hours before harvesting (see below), the right flank of each animal was shaved and $25 \mu \mathrm{g}$ of dialysed PPD was injected intradermally. The delayed hypersensitivity reaction was read at 24 hours using Schnelltaster Kröplin callipers A $02 \mathrm{~T}$ to measure the increase in skinfold thickness. The results are expressed as specific increases in skinfold thickness, which represent the reading $\left(10^{-1} \mathrm{~mm}\right)$ at the skin test site, minus the average thickness of the normal skin on both sides of the skin test site.

HARVEST ING

Animals were killed two weeks after inoculation in the case of BCG and at five weeks in the case of $M$ leprae. After terminal anaesthesia the abdomen was reopened through the original incision. After macroscopic inspection the inoculated area of bowel was excised, trimmed, and placed in $10 \%$ formol saline as were representative sections of the liver and spleen.

The ilecocolic and caecal lymph nodes draining primarily the ascending colon and the terminal ileum respectively were excised, weighed, and prepared for fixation in Carnoy's solution.

Specimens were processed in a standard manner, embedded in wax, and representative $5 \mu \mathrm{m}$ sections cut. In previous studies using this technique ${ }^{1}$ no significant increase in the area of granulomatous infiltration recorded was achieved by examining multiple sections. However, in this study where the area of granulomatous infiltration was found to be greatly reduced, further sections were cut through the block to ensure that the relevant area had not been missed. Sequential sections were stained with haematoxylin and eosin and Ziehl Neelsen stains. The coded sections were read by the same observer (ICM) and demarcated as negative or positive depending on the presence of granulomas on H\&E staining. If granulomatous infiltration was noted then its extent was measured using a projection microscope and planimeter.

In the case of lymph node sections, the areas of granulomatous infiltration and the total area of section were traced on to a white sheet using the projected image ( $\times 36$ magnification). The total area of section and the infiltrated area were measured using a fixed arm planimeter ( $1 \mathrm{rev}=$ $100 \mathrm{~cm}^{2}$, Constant 18728) and the area of granulomatous infiltration was expressed as a percentage of the total area. With bowel sections, a single representative field containing the inoculation site and all the granulomatous infiltration was chosen and this was measured in an identical manner. Student's $t$ test was used for statistical assessment of data. All the Ziehl Neelsen stained sections were scanned completely and the presence or absence of acid fast bacilli noted. 


\begin{tabular}{|c|c|c|c|c|}
\hline & \multicolumn{2}{|c|}{$\begin{array}{l}2 \times 10^{7} B C G \text { inoculated into the } \\
\text { terminal ileum }\end{array}$} & \multicolumn{2}{|c|}{$\begin{array}{l}2 \times 10^{\prime} \text { irradiated } \mathrm{M} \text { leprae inoculated } \\
\text { into the terminal ileum }\end{array}$} \\
\hline & $\begin{array}{l}\text { Ileocolic } \\
\text { node }\end{array}$ & Caecal node & Ileocolic node & Caecal node \\
\hline $\begin{array}{l}\text { Cyclophosphamide } 10 \mathrm{mg} / \mathrm{kg} \text { intraperitoneally daily } \\
\text { Methotrexate } 5 \mathrm{mg} \text { intraperitoneally on alternate days } \\
\text { Hydrocortisone } 0.6 \mathrm{mg} / \mathrm{g} \text { subcutaneously daily } \\
\text { Cyclosporin A in } 0.05 \mathrm{ml} \text { absolute alcohol } 50 \mathrm{mg} / \mathrm{kg}\end{array}$ & $\begin{array}{l}86 \cdot 5(22) \mathrm{NS} \\
69 \cdot 2(7) \mathrm{NS} \\
78 \cdot 3(17) \mathrm{NS}\end{array}$ & $\begin{array}{l}154(32) \mathrm{NS} \\
132 \cdot 8(0) \mathrm{NS} \\
172(52) \mathrm{NS}\end{array}$ & $\begin{array}{l}53 \cdot 3(11) \mathrm{p}<0.01 \\
110 \cdot 2(28) \mathrm{NS} \\
63(6.7) \mathrm{p}<0.05\end{array}$ & $\begin{array}{l}79 \cdot 3(24) \mathrm{p}<0 \cdot 001 \\
208 \cdot 3(50) \mathrm{NS} \\
137 \cdot 1(25) \mathrm{p}<0.01\end{array}$ \\
\hline $\begin{array}{l}\text { intramuscularly daily } \\
\text { Absolute alcohol } 0.05 \mathrm{ml} \text { intramuscularly daily } \\
\text { Untreated } \dagger\end{array}$ & $\begin{array}{l}73 \cdot 8(6) \mathrm{NS} \\
82 \cdot 8(11 \cdot 7) \mathrm{NS} \\
82 \cdot 3(21)\end{array}$ & $\begin{array}{l}157 \cdot 5(34) \mathrm{NS} \\
181 \cdot 8(32 \cdot 7) \mathrm{NS} \\
207(59)\end{array}$ & $\begin{array}{l}83 \cdot 6(15) \mathrm{NS} \\
130 \cdot 6(25)\end{array}$ & $\begin{array}{l}140(26) \mathrm{p}<0.01 \\
271.6(73)\end{array}$ \\
\hline
\end{tabular}

*Mean (SD) of six animals; † Mean (SD) of 12 animals.

NS = not significant in comparison with untreated controls by Student's $t$ test.

$\mathrm{p}=$ probability in comparison with untreated controls by Student's $t$ test.

\section{Results}

CLINICAL OBSERVATION

Animals in all the experimental groups were observed daily. None showed signs of clinical disease.

\section{SKIN TESTS}

Table I gives the skin test findings. Inoculation with BCG and subsequent treatment with any of the immune modulating agents caused an inhibition of the response to PPD $(\mathrm{p}<0.01$ except in the case of cyclosporin $A$ when $p<0.05$ ). Similarly, after inoculation with irradiated $M$ leprae subsequent treatment with any of the agents produced an inhibition of the response to PPD ( $p<0.01$ except in the case of treatment with cyclophosphamide when $\mathrm{p}<0.005)$. This inhibition was not observed in animals treated with absolute alcohol alone.

\section{LYMPH NODE WEIGHT}

Table II gives the mean lymph node weights. There was no reduction in either ileocolic or caecal lymph node weight in any of the BCG inoculated animals compared to the untreated controls. By contrast, animals inoculated with irradiated $M$ leprae showed a significant reduction in caecal lymph node weight when treated with cyclophosphamide $(\mathrm{p}<0.001)$, hydrocortisone $(p<0.01)$, or cyclosporin A $(p<0.01)$. A significant reduction was also noted in the weight of the ileocolic node in the animals receiving cyclophosphamide $(\mathrm{p}<0.01)$ or hydrocortisone $(\mathrm{p}<0.05)$.

\section{GRANULOMATOUS INFILTRATION AT THE} INOCULATION SITE AND PRIMARY AND SECONDARILY DRAINING LYMPH NODES (Table III)

Animals inoculated with BCG showed a significant reduction in granulomatous infiltration at the inoculation site after administration of either cyclophosphamide $(\mathrm{p}<0.05)$ or methotrexate $(\mathrm{p}<0.05)$. The latter group also showed a significant reduction of granulomatous infiltration of the caecal lymph node $(p<0.05)$. No other groups inoculated with BCG showed any reduction of granulomatous infiltration.

By contrast, animals inoculated with irradiated $M$ leprae showed a significant reduction of granulomatous infiltration both at the inoculation site $(\mathrm{p}<0.001)$ and in the caecal lymph node $(p<0.001)$ with all the drug treatments. A reduction in the ileocolic lymph node weight was seen after treatment with cyclophosphamide $(\mathrm{p}<0.001)$ and cyclosporin $A(p<0.01)$. No granulomas were observed in any of the liver or spleen sections.

\section{ZIEHL NEELSEN STAINING}

Animals inoculated with BCG showed an increased proportion with Ziehl Neelsen stained positive tissues at the inoculation site and in the draining lymph nodes when either hydrocortisone or methotrexate was administered.

TABLE III Terminal ileal and lymph node granulomatous infiltration as percentage of a representative field and total histological section respectively measured by planimetry (mean $(S D)$ )

\begin{tabular}{|c|c|c|c|c|c|c|}
\hline & \multicolumn{3}{|c|}{$\begin{array}{l}2 \times 10^{7} B C G \text { inoculated into the } \\
\text { terminal ileum }\end{array}$} & \multicolumn{3}{|c|}{$\begin{array}{l}2 \times 10^{9} \text { irradiated } \mathrm{M} \text { leprae } \\
\text { inoculated into the terminal ileum }\end{array}$} \\
\hline & $\begin{array}{l}\text { Terminal } \\
\text { ileum }\end{array}$ & $\begin{array}{l}\text { Ileocolic } \\
\text { node }\end{array}$ & $\begin{array}{l}\text { Caecal } \\
\text { node }\end{array}$ & $\begin{array}{l}\text { Terminal } \\
\text { ileum }\end{array}$ & $\begin{array}{l}\text { Ileocolic } \\
\text { node }\end{array}$ & $\begin{array}{l}\text { Caecal } \\
\text { node }\end{array}$ \\
\hline Cyclophosphamide $10 \mathrm{mg} / \mathrm{kg}$ intraperitonally daily ${ }^{\star}$ & $5 \cdot 1(5)$ & $4 \cdot 5(5 \cdot 4)$ & $20(23)$ & $\mathbf{0}$ & 0 & 0 \\
\hline Methotrexate $5 \mathrm{mg}$ intraperitoneally alternate days & $\begin{array}{l}\mathrm{p}<0 \cdot 03 \\
5 \cdot 1(12)\end{array}$ & $9 \cdot 4(15)$ & $10 \cdot 4(9)$ & $\begin{array}{l}\mathrm{p}<0.001 \\
0\end{array}$ & $\begin{array}{l}\mathrm{p}<0 \cdot 001 \\
19 \cdot 1(22)\end{array}$ & $\begin{array}{l}\mathrm{p}<0.001 \\
16.8(22)\end{array}$ \\
\hline & $p<0.05$ & NS & $p<0.05$ & $\mathrm{p}<0.001$ & NS & $\mathrm{p}<0.001$ \\
\hline Hydrocortisone $0.6 \mathrm{mg} / \mathrm{g}$ subcutaneously daily ${ }^{\star}$ & $\begin{array}{l}18(16) \\
\text { NS }\end{array}$ & $\begin{array}{l}8 \cdot 1(7) \\
\text { NS }\end{array}$ & $\begin{array}{l}17 \cdot 4(19) \\
\text { NS }\end{array}$ & $\begin{array}{r}3.93(7) \\
p<0.001\end{array}$ & $\begin{array}{l}23 \cdot 2(22) \\
\text { NS }\end{array}$ & $\begin{array}{c}3.9(7) \\
p<0.001\end{array}$ \\
\hline $\begin{array}{l}\text { Cyclosporin A } 50 \mathrm{mg} / \mathrm{kg} \text { in } 0.05 \mathrm{ml} \text { absolute alcohol } \\
\text { intramuscularly daily }\end{array}$ & $\begin{array}{l}9 \cdot 7(15) \\
\text { NS }\end{array}$ & $\begin{array}{l}11 \cdot 3(11) \\
\mathrm{NS}\end{array}$ & $\begin{array}{l}13(7) \\
\text { NS }\end{array}$ & $0<0.001$ & 0 & 0 \\
\hline Absolute alcohol $0.05 \mathrm{ml}$ intramuscularly daily ${ }^{\star}$ & $12 \cdot 2(13)$ & $12 \cdot 1(17)$ & $14 \cdot 3(6)$ & & & $P=0.00$ \\
\hline Untreated $\dagger$ & $21 \cdot 7(14)$ & $16(15)$ & $24 \cdot 4(13)$ & $36 \cdot 9(7)$ & $33 \cdot 5(10)$ & $62 \cdot 5(14)$ \\
\hline
\end{tabular}

*Mean (SD) of six animals; + Mean (SD) of 12 animals.

NS = not significant in comparison with untreated controls by Student's $t$ test.

$\mathrm{p}=$ probability by comparison with untreated controls by Student's $t$ test. 
TABLE IV Acid fast bacilli in tissues with Ziehl Neelsen staining (No positive/No sections)

\begin{tabular}{|c|c|c|c|c|c|c|}
\hline & \multicolumn{3}{|c|}{$\begin{array}{l}2 \times 10^{7} \text { BCG inoculated into } \\
\text { terminal ileum }\end{array}$} & \multicolumn{3}{|c|}{$\begin{array}{l}2 \times 10^{\circ} \text { irradiated } \mathrm{M} \text { leprae } \\
\text { inoculated into the terminal ileum }\end{array}$} \\
\hline & $\begin{array}{l}\text { Terminal } \\
\text { ileum }\end{array}$ & $\begin{array}{l}\text { Ileocolic } \\
\text { node }\end{array}$ & $\begin{array}{l}\text { Caecal } \\
\text { node }\end{array}$ & $\begin{array}{l}\text { Terminal } \\
\text { ileum }\end{array}$ & $\begin{array}{l}\text { Ileocolic } \\
\text { node }\end{array}$ & $\begin{array}{l}\text { Caecal } \\
\text { node }\end{array}$ \\
\hline Cyclophosphamide $10 \mathrm{mg} / \mathrm{kg}$ intraperitoneally daily & $1 / 6$ & $0 / 6$ & $0 / 6$ & $0 / 6$ & $0 / 6$ & $0 / 6$. \\
\hline Hydrocortisone $0.6 \mathrm{mg} / \mathrm{g}$ subcutaneously daily & $3 / 6$ & $1 / 6$ & $1 / 6$ & $0 / 6$ & $0 / 6$ & $0 / 6$ \\
\hline Methotrexate $5 \mathrm{mg}$ intraperitoneally alternate days & $4 / 6$ & $3 / 6$ & $3 / 6$ & $0 / 6$ & $0 / 6$ & $0 / 6$ \\
\hline \multirow{4}{*}{$\begin{array}{l}\text { Cyclosporin A } 50 \mathrm{mg} / \mathrm{kg} \text { in } 0.05 \mathrm{ml} \text { absolute alcohol } \\
\text { intramuscularly daily } \\
0.05 \mathrm{ml} \text { absolute alcohol intramuscularly daily } \\
\text { Untreated }\end{array}$} & & & & & & \\
\hline & $0 / 6$ & $0 / 6$ & $0 / 6$ & $0 / 6$ & $0 / 6$ & $0 / 6$ \\
\hline & $0 / 6$ & $0 / 6$ & $0 / 6$ & & & \\
\hline & $1 / 12$ & $0 / 12$ & $0 / 12$ & $0 / 12$ & $0 / 12$ & $0 / 12$ \\
\hline
\end{tabular}

However, no increase was seen in the other groups whether BCG or $M$ leprae was inoculated (Table IV).

\section{Discussion}

We used a previously delineated model $^{1}$ of epithelioid and phagocytic macrophage granulomas in the gastrointestinal tract of the guinea pig induced by the direct inoculation of BCG and $M$ leprae respectively. These studies showed that after inoculation of live BCG into the ascending colon or terminal ileum a granulomatous infiltration was induced at the inoculation site and the draining lymph nodes. This granulomatous infiltrate was significantly greater in the large bowel compared to the terminal ileum for a given inoculum. No significant difference in the extent of granulomatous infiltration was seen between the two inoculation sites when $M$ leprae was used.

Acid fast bacilli were present with Ziehl Neelsen staining of sections of the large bowel granulomatous infiltrate after BCG inoculation, but only rarely in sections from the terminal ileal lesions. There was a corresponding reduction in sensitivity to skin testing with PPD in animals inoculated in the small bowel. This is in contrast to the results of previous work ${ }^{12}$ which showed a greater skin test response with the same dose of PPD to live BCG and irradiated $M$ leprae at similar doses and time integers when inoculated in the guinea pig ear.

The model was used to observe the effect of four immune modulating agents on granuloma formation in the gut. Cyclophosphamide and methotrexate reduced the areas of infiltration of both types of granuloma in the gut. Hydrocortisone and cyclosporin $A$ reduced the area of infiltration of the phagocytic macrophage granuloma, but had no effect on the area of epithelioid granuloma infiltration. The response to PPD was reduced in all the treatment groups investigated.

Studies of the effect of cyclophosphamide and methotrexate on contact sensitivity in the guinea pig $^{23}$ showed that if cyclophosphamide was started within two days of sensitisation then this was inhibited. There was a drop in the proportion of large pyroninophilic cells or $\mathrm{T}$ immunoblasts in the local lymph node at a time when the $\mathrm{T}$ lymphocytes are known to go into their maximum proliferative phase.

Similar experiments using methotrexate again showed blockage of contact sensitivity but the action appeared to occur not directly on the large pyroninophilic cells but on the $T$ cells that developed from them. In our experiments an increased number of animals in the group treated with methotrexate after inoculation with BCG showed acid fast bacilli, but this was not observed in the $M$ leprae inoculated group. This may represent a drop in host resistance which could be related to decreased $\mathrm{T}$ lymphocyte function. Our findings are thus largely in keeping with those from earlier studies on contact sensitivity. It is perhaps surprising that cyclophosphamide had no effect on lymph node infiltration in the BCG granuloma. It is possible that this represents a difference in sensitivity or in the control process of the $\mathrm{T}$ lymphocyte subsets involved in the response to BCG. Previous studies using monoclonal antibodies on a model of similar granulomas induced in the posterior auricular lymph node of the guinea pig by the inoculation of these mycobacteria into the ear ${ }^{13}$ showed the presence on the epithelioid cells of macrophage specific antigen but little evidence of major histocompatibility complex class II antigen. In contrast, the macrophages of the $M$ leprae-induced granuloma expressed both macrophage specific and class II antigen. It thus appears that the epithelioid cells of a BCG induced granuloma share at least a close relationship with other cells of the mononuclear phagocyte series. A distinction between phagocytic macrophages and epithelioid cells in sarcoidosis and leprosy has also been observed in humans. ${ }^{14}$

Studies carried out using similar regimens of hydrocortisone and cyclosporin A on the BCG granuloma in the guinea pig ear model" showed that both reduced the skin test response to PPD. Neither agent, however, had any effect on the area of infiltration of the epithelioid cell granuloma. These findings agree with our observations. The macrophage granuloma induced by $M$ leprae was not studied. Electron microscope studies showed reduction in the rough endoplasmic reticulum of the epithelioid cells and this was considered suggestive of an effect of hydrocortisone and cyclosporin $A$ on the maturation of macrophages into epithelioid cells. This alteration in epithelioid cell morphology on electron microscopy may account for the increased number of animals seen in the hydrocortisone treated group with acid fast bacilli detectable with Ziehl Neelsen staining in both the bowel wall and the draining lymph nodes. By contrast in the experiments using the guinea pig ear model" the only acid fast bacilli observed were degraded organisms seen with the electron microscope in the cyclosporin A treated group. 
It has been postulated that epithelioid cell maturation may be lymphokine mediated, ${ }^{15}$ although published reports are contradictory regarding the effects of glucocorticoids on lymphokine production and the ability of macrophages to respond to them. ${ }^{16-19}$ The reduced response to $M$ leprae after treatment with hydrocortisone seen in our experiments may be related to a reduced level of prostaglandin $E_{2}$ and leucotrienes, which act as macrophage activators. They are believed to play an important part in modulating the immune response in ulcerative colitis $^{2021}$ and levels have been shown to correlate well with disease activity and fall towards control levels after treatment with prednisolone..$^{22}$

Cyclosporin A is believed to exert its effects by selectively influencing the clonal expansion and activation of individual $\mathrm{T}$ lymphocyte subsets by blocking the synthesis or release of interleukin 1 and interleukin 2 from monocytes and $\mathrm{T}$ helper cells respectively. ${ }^{23}$ It also favours the expansion of antigen specific suppressor $\mathrm{T}$ cells $\mathrm{s}^{24}$ and thus acts at an early stage in the immune response leaving the established immunological memory intact. ${ }^{25}$

Guinea pigs treated with cyclosporin A have been shown to have a reduced production of lymphokines in vitro ${ }^{26}$ and this may explain the reduced response to PPD. The lack of effect on infiltration of an epithelioid cell granuloma in the bowel wall is also in keeping with the finding that prolonged treatment with cyclosporin A failed to prevent the formation of new granulomas in mice receiving subcutaneous implants of hepatic schistosomal granulomas. ${ }^{27}$ Here some $\mathrm{T}$ lymphocyte function had returned by three weeks, suggesting that cyclosporin resistant clones had been stimulated. These results are in keeping with the results of the treatment of Crohn's disease with cycloporin in humans first reported in $1984,{ }^{6}$ where present results indicate a variable rate of response with relapse being common after treatment is stopped. ${ }^{728}$

A marked reduction in macrophage activating factor has been noted in mice treated with higher doses of cyclosporin A $(70 \mathrm{mg} / \mathrm{kg} /$ day $) .{ }^{29} \mathrm{It}$ is possible that this effect on lymphokine production is responsible for the failure of formation of a macrophage granuloma in response to $M$ leprae in our model.

It is of interest that, clinically, Crohn's disease shows a considerable variation in its response to treatment with a variety of immunosuppressive agents. The lack of response to hydrocortisone and cyclosporin A seen in the live BCG induced bowel granulomas, which has the closest histological resemblance to Crohn's disease in our models, may be analogous to this.

In conclusion, it may be that the variation in response achieved clinically in patients with Crohn's disease using either glucocorticoids or cyclosporin A represents the overall balance of effect on a series of $\mathrm{T}$ lymphocyte subsets with differing potentials and susceptibilities. The trial of other therapeutic agents used in the treatment of clinical Crohn's disease, together with further work using monoclonal antibodies against differing $T$ cell subsets might be of value in elucidating these observations.
We wish to thank Miss $\mathrm{M}$ Jacques, $\mathrm{Mr} \mathrm{F}$ Schindler, and $\mathrm{Mr} \mathrm{P}$ Papasavva for their excellent technical assistance, and Mrs J Saxby for typing the manuscript. We also gratefully acknowledge the for typing the manuscript. We also gratefully acknowledge the financial support of the Lilian
College of Surgeons of England.

1 Mitchell IC, Turk JL. An experimental animal model of granulomatous bowel disease. Gut 1989; 30: 1371-8

2 Turk JL, Stone S. Implications of the cellular changes in lymph nodes during the development and inhibition of delayed type hypersensitivity. In: Amos' and Koprowski's cellbound antibodies. Wistar Institute Press, 1963: 51-60.

3 Turk JL. Studies on the mechanism of action of methotrexate and cyclophosphamide on contact sensitivity in the guinea pig. Int Arch Allergy 1964; 24: 191-200.

4 Summers RW, Switz PM, Sessions JT Jr, et al. National cooperative Crohn's disease study: results of drug treatment. Gastroenterology 1979; 77: 847-69.

5 Bord JF, Feurer C, Guhler HU, Stähelin H. Biological effects of cyclosporin A: a new antilymphocytic agent. Agents Action of cyclosporin A

6 Allison MC, Pounder RE. Cyclosporin for Crohn's disease. Lancet 1984; i: 1902 .

7 Parratt NR, Taylor RMR, Venables CW, Record CO. Treatment of Crohn's disease in relapse with cyclosporin A. $\mathrm{Br} \mathcal{F}$ Surg 1988; 75: 1185-8

8 Miles AA, Misra SS. The estimation of bactericidal power of the blood. $\mathcal{F}$ Hyg 1938; 38: 732 .

9 Hart PD, Rees RJW. Effect of macrocyclon on acute and chronic pulmonary tuberculosis infection in mice as shown by viable and total bacterial counts. Br f Exp Pathol 1960; 41: 414-21.

10 Dwyer JM, Parker D, Turk JL. Suppression of delayed hypersensitivity to tuberculin by antigenic competition: a hypersensitivity to tuberculin by antigenic competition: a positive immunoregulatory mechanism sensit

11 Gupta SK, Curtis J, Turk JL. The effect of hydrocortisone and cyclosporin A on bacillus Calmette-Guerin epithelioid cell granulomas. Cell Immunol 1985; 93: 189-98.

12 Narayanan RB, Badernoch-Jones P, Curtis J, Turk JL. Comparison of mycobacterial granulomas in guinea pig lymph nodes. F Pathol 1982; 138: 219-33.

13 Mathew RC, Katayama I, Gupta SK, Curtis J, Turk JL. Analysis of cells of the mononuclear phagocyte series in experimental mycobacterial granulomas by monoclonal antibodies. Infect Immun 1983; 39: 344-52.

14 Munro CS, Campbell DA, Collings LA, Poulter LW. Monoclonal antibodies distinguish macrophages and epithelioid cells in sarcoidosis and leprosy. Clin Exp Immunol 1987; 68: cells in 7 .

15 Schmidt ME, Douglas SD, Rubin AD. Human monocyte activation by supernatants from concanavalin A (Con A)

16 Balaw JE, Rosenthal AS. Glucocorticoid suppression of macrophage migration inhibitory factor. $\mathcal{F} \operatorname{Exp} M e d 1973$ 137: $1031-41$

17 Bendtzen K. Drug effects on human lymphocyte migration and migration inhibitory activity from lymphocytes stimulated with concanavalin A. Acta Path Microbiol Immunol Scand [C] 1975; 83: 447-54.

18 Balaw JE, Hurley DL, Fauci AS. Immunosuppressive effects of glucocorticosteroids: differential effects of acute vs chronic administration on cell mediated immunity. chronic administration on

19 Weston WL, Claman HN, Krueger CG. Site of action of cortisol in cellular immunity. F Immunol 1973; 110: 880-3.

20 Hawkey CJ, Truelove SC. Effects of prednisolone on prostaglandin synthesis by rectal mucosa in ulcerative colitis investigation by laminar flow bioassay and radioimmunoassay. Gut 1981; 22: 190-3.

21 Lauritsen K, Staerh Laursen L, Bukhave K, Rash-Madsen J. In vivo effects of orally administered prednisolone on prostaglandin and leucotriene production in ulcerative colitis. Gut 1987; 28: 1095-9.

22 Lauritsen K, Laursen LS, Bukhave K, Rash-Madsen J. Effects of topical 5-aminosalicylic acid and prednisolone on prostaglandin $\mathrm{E}_{2}$ and leukotriene $\mathrm{B}_{4}$ synthesis determined by equilibrium in vivo dialysis of rectum in relapsing ulcerative colitis. Gastroenterology 1986;91: 837-44.

23 Burjes D, Hardt C, Rollinghoff H, Wagner M. Cyclosporin A mediates immunosuppression of primary cytotoxic $\mathrm{T}$-cell responses by impairing the release of interleukin I and interleukin II. Eurf Immunol 1981; 11: 657-61

24 Kupiec-Weglinski JW, Filho MA, Strom TB, Tilney NL. Sparing of suppressor cells: a critical action of cyclosporine. Transplantation 1984; 38: 97-101

25 Wang BS, Meacoch EH, Collins KH, Hutchinson IF, Tilney NL, Mannich JA. Suppressive effects of cyclosporin A on the induction of alloreactivity in vitro and in vivo. 7 Immunol 1981; 127: 89-93.

26 Thompson AW, Moon DK, Geczy CL, Nelson DS. Cyclosporin A inhibits lymphokine production, but not the im to lymphokines. Immunolo 1983; 48: 291-9.

27 Suya H, Fujiaka A, Pincelli C, Fukuyama K, Epstein WL. Skin granuloma formation in mice immunosuppressed by cyclosporine. F Invest Dermatol 1988; 90: 430-3.

28 Allison MC, Pounder RE. Cyclosporin for Crohn's disease. Allison MC, Pounder RE. Cyclosporin fo

29 Alberti S, Boraschel D, Liuni W, Tagliabue A. Effects of in vivo treatments with cyclosporin A on mouse cell mediated vivo treatments with cyclosporin A on mouse cell mediated
immune responses. Int $\mathcal{F}$ Immunopharmacology 1981; 3: 35764 . 